\title{
Role of Multislice Computed Tomography in Acute Right Lower Quadrant Abdominal Pain
}

\author{
ASMAA Y. AL-KASABI, M.Sc.*; KHALED I. EL-SHAFEY, M.D.*; HALA M. EL-GENDY, M.D.** and \\ AL-SHAYMAA Z. EL-SHAHAWY, M.D.* \\ The Departments of Radio-Diagnosis \& Medical Imaging* and Anesthesiology \& Surgical Intensive Care**, \\ Faculty of Medicine, Tanta University
}

\begin{abstract}
Background: Acute appendicitis is the most widely recognized reason for right lower quadrant pain. However, various different conditions may cause signs and symptoms that mimic acute appendicitis. Multislice Computed Tomography (MSCT) is currently viewed as the imaging modality of choice in patients presenting with right lower quadrant abdominal pain as it helps to make a definitive diagnosis in most of the cases.

Aim of Study: To evaluate the role of MSCT in the identification of numerous etiologies in patients with acute right lower quadrant abdominal pain.

Patients and Methods: This work was conducted on thirty patients (20 females and 10 males) who presented with acute right lower quadrant abdominal pain. All patients underwent to detailed history taking, clinical examination, laboratory studies, ultrasound examination and MSCT scanning of the abdomen and pelvis. The correlation was done between the MSCT findings and the final diagnosis. The final diagnosis was made by operative procedures, laparoscopy, histopathological results and conservative management.
\end{abstract}

Results: There were 17 patients $(56.6 \%)$ with acute appendicitis and appendiceal complications, 6 females (20\%) with acute gynecological diseases, 4 patients $(13.3 \%)$ with other acute gastrointestinal (GIT) diseases and 3 patients $(10 \%)$ with acute urological diseases. There were 24 patients went through surgery or laparoscopy, 6 patients were managed conservatively with close follow-up. The sensitivity of MSCT in our study was highest in acute GIT diseases and acute urological diseases, then appendicular diseases and the last in acute gynecological diseases.

Conclusion: Multislice CT is a significantly valuable noninvasive imaging method for identification and assessment of the most recognized reasons such as appendicitis in addition to the less known conditions.

Key Words: Emergency - Right lower quadrant abdominal pain-Multislice CT-Appendicitis - Differential diagnosis.

Correspondence to: Dr. Asmaa Youssri Al-Kasabi, The Department of Radio-Diagnosis \& Medical Imaging, Faculty of Medicine, Tanta University

\section{Introduction}

RIGHT lower quadrant pain is one of the most commonly recognized reasons behind a patient admission to the emergency room. In spite of the appendicitis is that the most frequent reason for surgery in patients have abdominal pain. Right lower quadrant abdominal pain can be indicative of different conditions which may cause clinical manifestations that mimic acute appendicitis and therefore can be challenging for clinicians [1] .

The correct diagnosis may be challenging especially when the patient cannot localize the site of pain and there are overlapping clinical pictures, physical examination, and laboratory information [2].

Despite the clinical presentation of periumbilical pain transferring to the right lower abdominal quadrant is traditionally related to acute appendicitis, the presentation is not regularly classic and therefore the accurate diagnosis cannot constantly be based on the patient's history and clinical examination only. An early and accurate diagnosis leads to more accurate management and, subsequently, result in better outcomes [3,4]

Ultrasound (US) with graded compression technique has been utilized as a noninvasive, nonionizing radiation imaging tool for diagnosing acute appendicitis. Unluckily, ultrasound determines numerous limitations. The most common limitation is that the appendix is not constantly visualized, even for skilled sonographers [5].

The need for rapid and correct diagnosis has encouraged the extended utilization of computed tomography in recent decades. Different studies have shown that CT is a great useful tool in patients 
with acute abdominal pain, improving the diagnosis and resulting in a modification of management [6]

MSCT has established to be an impressively valuable noninvasive technique for assessment of patients with Right Lower Quadrant Pain (RLQP). The utilization of MSCT leads to diminishing the proportions of negative appendectomies and related morbidity, the duration of hospitalization, and the expense of patient nursing [7].

Recent advances in MSCT enable the acquisition of high-quality multiplanar reformations, which have been informed to improve the imagining of the appendix which can strengthen the sureness of a negative test result [8].

The usage of intravenous and oral contrast can raise the sensitivity of the CT examination for diagnosing of appendicitis and different pathologies than acute appendicitis, enteric and Intravenous (IV) contrast might be more helpful in patients who lack adequate mesenteric fat [9]

\section{Patients and Methods}

This study was performed on thirty patients (20 females and 10 males), their ages ranged from 13 to 85 years old with a mean age of $(37.0 \pm 18.73)$. This study was carried out on the Radiodiagnosis and Medical Imaging Department, Tanta University from the period between September 2016 and August 2018.

Cases were referred to the Radiodiagnosis and Medical Imaging Department from the Emergency Department. The study included patients who presented with ARLQP (acute right lower quadrant pain) especially those have atypical presentations and expressed difficulties in defining the etiology. Patients with chronic abdominal pain also pregnant women were excepted from the work.

The study protocol was approved by the Research Ethics Committee of the Faculty of Medicine, Tanta University.

All the studied patients were subjected to detailed medical history with stressing on the criteria of the abdominal pain (onset, duration, severity, site, and migration), clinical examination, laboratory investigations, ultrasound examination of the abdomen and pelvis and MSCT scan of the abdomen and pelvis. The feedback of the operative procedures, laparoscopy, histopathological results and conservative management were obtained.

All patients underwent an initial ultrasonographic examination of the abdomen and pelvis which had been done as a routine survey of all abdominal organ. The study was carried out by using the electronic phased array probe of frequency range: $1-5 \mathrm{MHz}$ for a trans-abdominal ultrasound, patients were asked to point to the region of the most tenderness with one finger, the right iliac fossa was then scanned by using frequency range: 5-13 MHz. Graded compression technique had been used to evaluate the right iliac fossa. As the compression was applied to the transducer, bowel gas and content were displaced and intra-abdominal structures were brought closer to the transducer.

All patients underwent MSCT examination of abdomen and pelvis. The examination was performed in the recumbent position, from the dome of the diaphragm to the symphysis pubis in a single hold breath using 16 slices/rotation and 128 slices/ rotation MSCT machines. The scanning parameters applied were: $160-350 \mathrm{mAs}, 120 \mathrm{KVP}$, tube rotation time of $0.75 \mathrm{~s} /$ rotation for 16 slices MSCT machine and $0.3 \mathrm{~s} /$ rotation for 128 slices MSCT machine, $1-2 \mathrm{~mm}$ slice thickness and $1.25 \mathrm{~mm}$ reconstruction increment.

21 patients were scanned without injection of intravenous contrast agent, whereas 9 patients were scanned with injection of IV contrast agent and one patient of them with suspected right iliac fossa mass was examined following IV contrast injection with the administration of an oral neutral contrast agent (1.5-2L of water and $500 \mathrm{ml}$ of $3 \%$ mannitol) and neutral enema contrast was administered $(600 \mathrm{~mL}$ to $1 \mathrm{~L}$ of water) via a soft catheter with a balloon. The post-contrast exam was obtained in the portal venous stage at 40 seconds. The IV contrast agent was utilized of the non-ionic type namely (Iopromide $300 \mathrm{mg} / \mathrm{mL}$ ) using a dose of $1.5 \mathrm{mg} / \mathrm{kg}$. The automated injection was utilized and the contrast agent infused at a rate of $3 \mathrm{ml} / \mathrm{s}$ via the antecubital vein. All the patients who were given contrast agents had normal serum creatinine.

The MSCT pictures were reconstructed by filtered reconstruction algorithms. The thin cuts were sent to the workstation, after reconstruction of the raw information via medium soft tissue reconstruction processes, where they were accessible to be seen in axial, sagittal and coronal planes.

In every patient, the right iliac fossa was evaluated for the following: The site of the appendix, the presence of inflammatory changes, enlargement of the diameter of the appendix $\geq 7 \mathrm{~mm}$; thickened wall with enhancement (evaluated in 9 patients were scanned with injection of IV contrast agent), appendicolith; periappendiceal fat stranding or 
fluid collection; focal thickening of the cecum, mesenteric fat stranding; as well as assessment of the related complications including appendicular mass, appendicular abscess, mucocele formation. Alternative gastrointestinal reasons of pain as diverticulitis and intussusception, urological causes as ureteric stones, and gynecological causes as complicated cysts were additionally assessed. The whole abdomen has also been assessed as a routine in all patients with acute abdominal pain.

\section{Results}

The final diagnosis of the studied sample was based on surgical operation, laparoscopy, histopathological results of the excised lesions, conservative treatment and follow-up on a combination of laboratory tests and the imaging studies.

According to the affected system in the right lower quadrant of the abdomen, the studied sample classified into four groups: Group A including patients with acute appendicitis and appendiceal complication, Group B including patients with other acute gastrointestinal diseases, Group C including female patients with acute gynecological diseases, Group D including patients with acute urological diseases.

The patients in the current study were having variable symptoms with a high degree of overlap. All patients in our study had Acute Right Lower Quadrant Pain (ARLQP), 15 of them had ARLQP alone and the other 15 patients had ARLQP associated with other sites of pain ( 8 patients had associated diffuse abdominal pain, 6 patients had associated pelvic pain, 1 patient had associated right loin pain). The second most common clinical picture was a fever in 11 patients (36.7\%), and the less common clinical findings in our study were dysuria and palpable right iliac fossa mass, which were presented in 2 patients $(6.7 \%)$.

There were 17 patients $(56.6 \%)$ with acute appendicitis and appendiceal complications (11 patients with acute appendicitis and 6 patients with appendiceal complications which included 1 with stump appendicitis, 1 with appendiceal mucocele, 3 patients with perforated appendix, 1 patient had appendicitis with phlegmon), 4 patients (13.3\%) with other acute gastrointestinal (GIT) diseases (1 with right colonic and cecal diverticulitis, 1 with cecal cancer, 1 had cecal cancer with perforation and abscess formation, 1 with ileocecal intussusception), 6 females (20\%) with acute gynecological diseases (1 with right functional ovarian cyst, 1 with endometriosis, 1 with rupture right hemor- rhagic cyst, 1 with right hemorrhagic cyst, 1 with rupture right dermoid cyst, 1 with right ectopic pregnancy), 3 patients (10\%) with acute urological diseases (1 with right renal and right lower ureteric stones, 1 with right vesicoureteric stone, 1 right renal and right mid ureteric stones) (Table 1).

The MSCT findings in our patients with acute appendicitis and appendiceal complications were increased appendiceal diameter $\geq 7 \mathrm{~mm}$ (from outer wall to outer wall) in 14 patients $(82.35 \%)$, fecolith in 4 patients $(23.5 \%)$, stranding of the surrounding fat planes in 10 patients $(58.82 \%)$, free intraperitoneal fluid collection in 8 patients $(47 \%)$, reactive mesenteric lymph nodes at the right iliac fossa in 6 patients (35.29\%), and diffuse wall thickening of the cecum and terminal ileum in 2 patients (11.76\%). In complicated cases, the presence of loculated collections with marginal enhancement \pm air foci in 2 patients $(11.76 \%)$, a defect in the wall of the appendix (interrupted wall) in 3 patients $(17.64 \%)$.

As regards the group with other acute GIT diseases, there were 4 patients had right-sided diverticulitis, cecum cancer, cecum cancer with perforation and abscess formation, and ileocecal intussusception (Table 2).

In the group with acute gynecological diseases, there were 6 patients had a right functional ovarian cyst, endometriosis, rupture right dermoid cyst, rupture right hemorrhagic cyst, right hemorrhagic cyst and right ectopic pregnancy (Table 3 ).

As regards the group with acute urological diseases, the MSCT findings in our patients were two hyperdense stones at the distal third of the right ureter with back pressure effect in the form of minimal hydronephrosis with minimally related fat stranding and right renal lower calyceal hyperdense stone found in one patient. Another patient had a hyperdense stone at the right renal pelvis with another one hyperdense stone at the middle third ureter. The last patient had a hyperdense stone at the right vesicoureteric junction with minimal right hydroureteronephrosis.

Regarding the final (definite) diagnosis of all 30 patients had acute right lower quadrant pain; there was a significant relationship with MSCT findings in acute appendicitis and appendiceal complications group and acute urological diseases group (Table 4).

In our study, MSCT had a good diagnostic role (accuracy) in acute GIT diseases and acute Urological diseases, next in acute gynecological 
diseases and appendicular diseases. The sensitivity of MSCT was highest in acute GIT diseases and
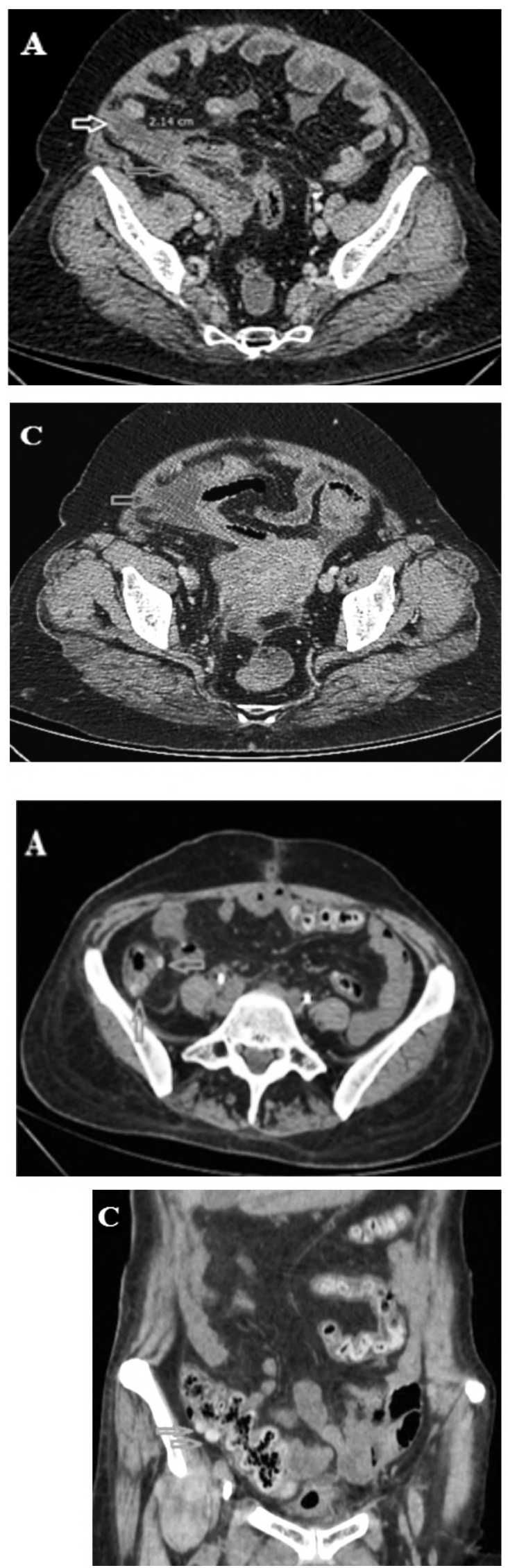

acute urological diseases, then appendicular diseases, then acute gynecological diseases (Table 5).

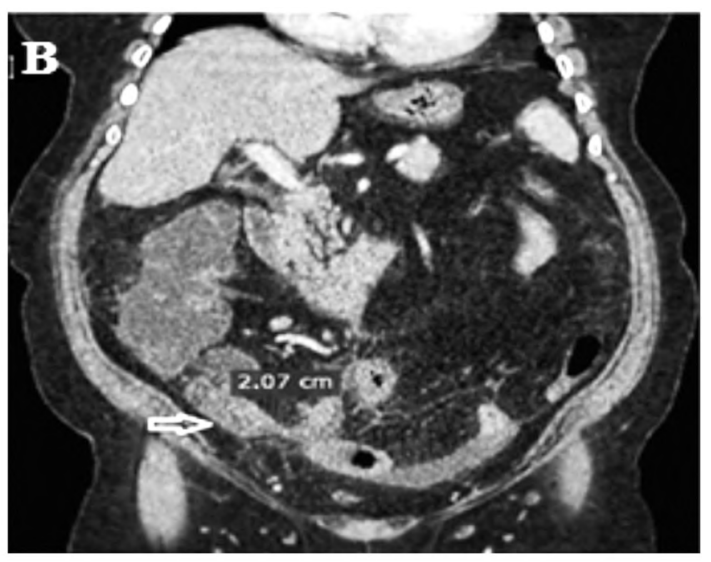

Fig. (1): Perforated appendix in female patient 65 years old, complained of acute right iliac fossa pain. Contrast MSCT, (A-C) axial images: Showing fluidfilled appendix (yellow arrow), measuring $20 \mathrm{~mm}$ with interrupted tip surrounded by the mild amount of collection (red arrow) and fat stranding.

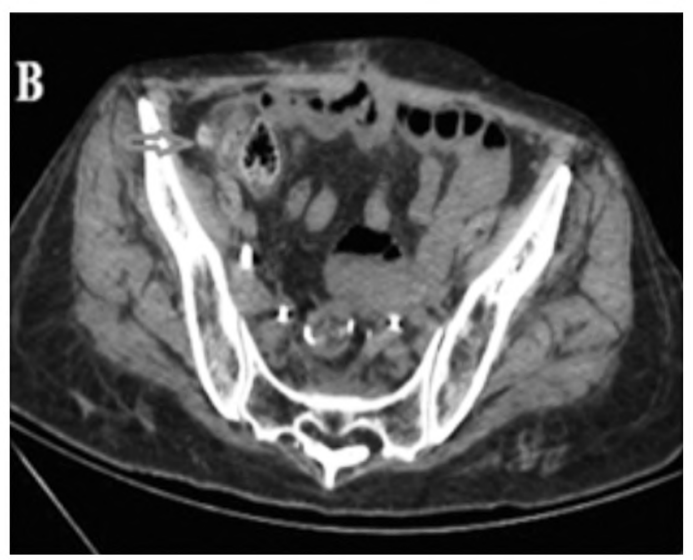

Fig. (2): Right colonic and cecal diverticulitis in female patient 50 years old, complained of acute right iliac fossa pain with a history of intermittent pain in the same area for two weeks, changes in bowel habits. Non-contrast CT, (A,B): Axial images and $(\mathrm{C})$ : Coronal image showing multiple hyperdense outpunching (red arrow) seen arising from the cecal wall and ascending colon. 

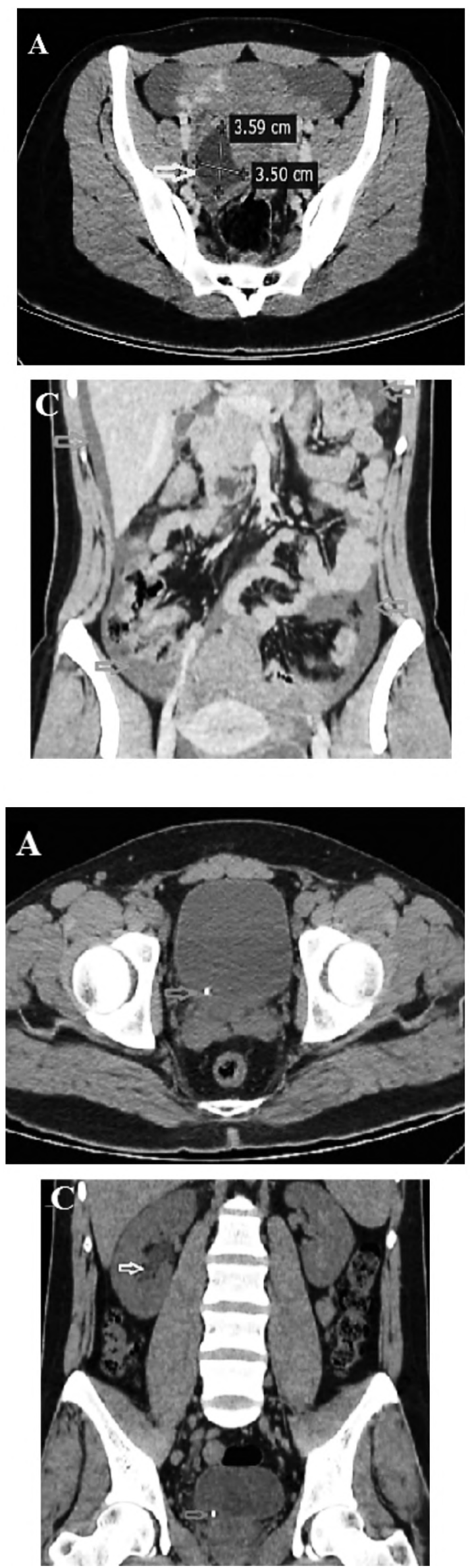

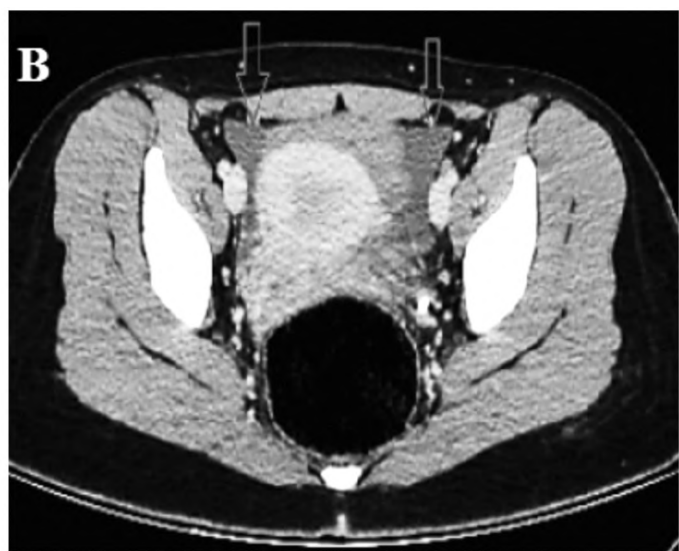

Fig. (3): Rupture right ovarian hemorrhagic cyst in female patient 21 years old, complained of acute right iliac fossa pain, fever and irregular menses. Contrast MSCT, (A,B): Axial images and (C): Coronal image showing right ovary containing cyst (yellow arrow), measuring $3.5 \times 3.5 \mathrm{~cm}$, its density $29 \mathrm{HU}$, surrounded by the mild amount of collection. Other sites of collection seen all over the abdomen (red arrows).

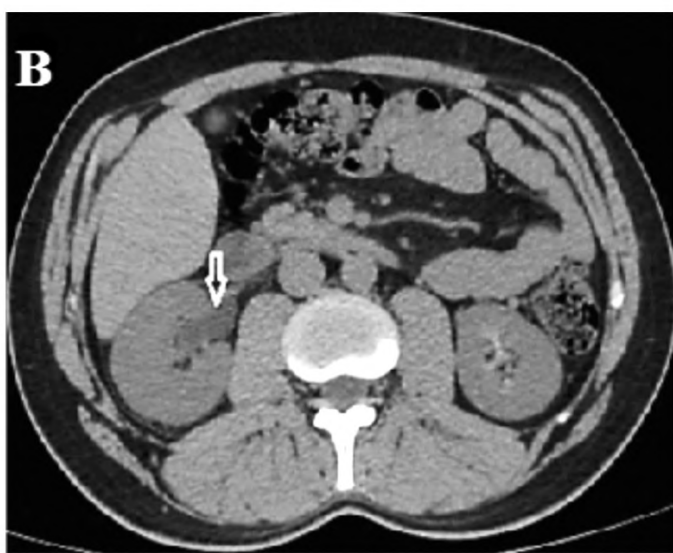

Fig. (4): Right vesicoureteric stone in male patient 29 years old, complained of right iliac fossa pain, nausea and vomiting. Non-contrast MDCT, (A,B): Axial images and (C): Coronal image showing stone at the right vesicoureteric junction (red arrow), measuring $6 \mathrm{~mm}$, with minimal right hydroureteronephrosis (yellow arrow). 
Table (1): Distribution of the patients according to a final diagnosis in both sexes and the percentage of that diagnosis from the total number of patients.

\begin{tabular}{|c|c|c|c|c|}
\hline Final diagnosis & $\begin{array}{c}\text { Number of } \\
\text { patients }\end{array}$ & Male & Female & $\begin{array}{l}\text { Percentage } \% \text { to total } \\
\text { no. of patients }\end{array}$ \\
\hline $\begin{array}{l}\text { Acute appendicitis and appendiceal complication: } \\
\text { Acute appendicitis } \\
\text { Stump appendicitis (post appendectomy abscess) } \\
\text { Mucocele appendicitis } \\
\text { Perforated appendix } \\
\text { Appendicitis with phlegmon }\end{array}$ & $\begin{array}{l}17 \\
11 \\
1 \\
1 \\
3 \\
1\end{array}$ & $\begin{array}{l}7 \\
6\end{array}$ & $\begin{array}{l}10 \\
5 \\
1 \\
1 \\
2 \\
1\end{array}$ & $56.6 \%$ \\
\hline $\begin{array}{l}\text { Other acute GIT diseases: } \\
\text { Right-sided diverticulitis } \\
\text { Cecal cancer } \\
\text { Cecal cancer with perforation and abscess formation } \\
\text { Ileocecal intussusception }\end{array}$ & $\begin{array}{l}4 \\
1 \\
1 \\
1 \\
1\end{array}$ & $\begin{array}{l}1 \\
- \\
1\end{array}$ & $\begin{array}{l}3 \\
1 \\
1 \\
1 \\
-\end{array}$ & $13.3 \%$ \\
\hline $\begin{array}{l}\text { Acute gynecological diseases: } \\
\text { Right functional ovarian cyst } \\
\text { Endometriosis } \\
\text { Rupture right dermoid cyst } \\
\text { Rupture right hemorrhagic cyst } \\
\text { Right hemorrhagic cyst } \\
\text { Right ectopic pregnancy }\end{array}$ & $\begin{array}{l}6 \\
1 \\
1 \\
1 \\
1 \\
1 \\
1\end{array}$ & $\begin{array}{l}- \\
- \\
- \\
- \\
- \\
-\end{array}$ & $\begin{array}{l}6 \\
1 \\
1 \\
1 \\
1 \\
1 \\
1\end{array}$ & $20 \%$ \\
\hline $\begin{array}{l}\text { Acute urological diseases: } \\
\text { Right kidney and right lower ureteric stones } \\
\text { Right kidney and right mid ureteric stones } \\
\text { Right vesicoureteric stone }\end{array}$ & $\begin{array}{l}3 \\
1 \\
1 \\
1\end{array}$ & $\begin{array}{l}2 \\
1 \\
1\end{array}$ & $\begin{array}{l}1 \\
- \\
1\end{array}$ & $10 \%$ \\
\hline
\end{tabular}

Table (2): The MSCT findings in the patients in our study with other acute GIT diseases.

\begin{tabular}{ll}
\hline Other acute GIT diseases & The MSCT findings in the patients \\
\hline - Right-sided diverticulitis & $\begin{array}{l}\text { - Multiple inflamed diverticula at the cecum and ascending colon, peridiverticular inflammation } \\
\text { and minimal fluid collection. }\end{array}$ \\
- Cecum cancer & $\begin{array}{l}\text { Asymmetrical increase of the colonic wall thickness with a short section of involvement, } \\
\text { an abrupt change from a normal to an abnormal section of the colon with related multiple } \\
\text { enlarged lymph nodes (proved by histopathology). }\end{array}$ \\
$\begin{array}{l}\text { - Cecum cancer with perforation } \\
\text { and abscess formation }\end{array}$ & $\begin{array}{l}\text { Irregular circumferential wall thickening of the cecum, loculated fluid collection at the } \\
\text { right paracolic area with air foci and multiple hyperdense foci, surrounding fat stranding } \\
\text { and associated multiple enlarged lymph nodes (proved by histopathology). }\end{array}$ \\
- Ileocecal intussusception & $\begin{array}{l}\text { Target-shaped bowel within-bowel appearance, with a leading mass in the ileum, appeared } \\
\text { as intraluminal fat density lesion (confirmed by histopathology as intestinal lipoma). }\end{array}$ \\
\hline
\end{tabular}

Table (3): The MSCT findings in the patients in our study with acute gynecological diseases.

\begin{tabular}{|c|c|}
\hline Acute gynecological diseases & The MSCT findings in the patients \\
\hline - Right functional ovarian cyst & - Right adnexal cyst of the fluid density measuring $3 \times 1 \mathrm{~cm}$. \\
\hline - Endometriosis & $\begin{array}{l}\text { - MSCT findings in a patient with a history of endometriosis after cesarean section: A mild } \\
\text { free intraperitoneal fluid collection showing partially loculated component of attenuation } \\
\text { greater than simple fluid ( } 28 \mathrm{HU}) \text { noted at the pelvis, marked fat stranding related to the } \\
\text { right iliac fossa region, right adnexal cyst with thick enhancing wall and multiple reactive } \\
\text { lymph nodes. }\end{array}$ \\
\hline - Rupture right dermoid cyst & $\begin{array}{l}\text { - Right cystic adnexal lesion measuring } 9 \times 5 \mathrm{~cm} \text { with mixed fat fluid and calcium densities } \\
\text { which surrounded by a mild collection of same density of fluid with multiple septations. }\end{array}$ \\
\hline - Rupture right hemorrhagic cyst & $\begin{array}{l}\text { - Right ovarian cyst measuring } 3.5 \times 3.5 \mathrm{~cm} \text { with heterogeneity (with internal attenuation } \\
\text { was } 28 \mathrm{HU} \text { ), surrounded with the mild fluid collection and presence of free fluid collection } \\
\text { noted all over the abdomen. The diagnosis proved by surgery. }\end{array}$ \\
\hline - Right hemorrhagic cyst & $\begin{array}{l}\text { - Right ovarian cyst with internal attenuation } 30 \mathrm{HU} \text {, measuring } 4 \times 3 \mathrm{~cm} \text {. The diagnosis } \\
\text { proved by surgery. }\end{array}$ \\
\hline - Right ectopic pregnancy & $\begin{array}{l}\text { - Right adnexal structure measuring } 6 \text { X 5cm, surrounding minimal fluid collection and } \\
\text { mild stranding of fat planes. } \\
\text { - MSCT result was false negative and the diagnosis proved by surgery. }\end{array}$ \\
\hline
\end{tabular}


Table (4): Distribution of all cases of right lower quadrant pain according to final diagnosis compared with MSCT results.

\begin{tabular}{|c|c|c|c|c|c|c|}
\hline \multirow[b]{2}{*}{ Final diagnosis } & \multicolumn{4}{|c|}{ MSCT result } & \multicolumn{2}{|c|}{ Chi-square } \\
\hline & $\begin{array}{l}\text { Diagnostic } \\
\text { (no. of cases) }\end{array}$ & $\begin{array}{l}\text { Suggestive } \\
\text { (no. of cases) }\end{array}$ & $\begin{array}{c}\text { False }(-\mathrm{ve}) \\
\text { (no. of cases) }\end{array}$ & $\begin{array}{l}\text { Total no. } \\
\text { of cases }\end{array}$ & $x^{2}$ & $\begin{array}{c}p- \\
\text { value }\end{array}$ \\
\hline Acute appendicitis and appendiceal complications: & 13 & 2 & 2 & 17 & 21.353 & $<0.001 * *$ \\
\hline Acute appendicitis & 8 & 1 & 2 & 11 & & \\
\hline Stump appendicitis (post appendectomy abscess) & & 1 & - & 1 & & \\
\hline Mucocele appendicitis & 1 & - & - & 1 & & \\
\hline Perforated appendix & 3 & - & - & 3 & & \\
\hline Appendicitis with phlegmon & 1 & - & - & 1 & & \\
\hline Other acute GIT diseases: & 3 & 1 & - & 4 & 5.250 & 0.072 \\
\hline Right-sided diverticulitis & 1 & & - & 1 & & \\
\hline Cecum cancer & 1 & & - & 1 & & \\
\hline Cecum cancer with perforation and abscess formation & & 1 & - & 1 & & \\
\hline Ileocecal intussusception & 1 & - & - & 1 & & \\
\hline Acute gynecological diseases: & 2 & 3 & 1 & 6 & 1.500 & 0.472 \\
\hline Right functional ovarian cyst & - & 1 & - & 1 & & \\
\hline Endometriosis & & 1 & - & 1 & & \\
\hline Rupture right dermoid cyst & 1 & & - & 1 & & \\
\hline Rupture right hemorrhagic cyst & & 1 & - & 1 & & \\
\hline Right hemorrhagic cyst & 1 & - & & 1 & & \\
\hline Right ectopic pregnancy & - & - & 1 & 1 & & \\
\hline Acute urological diseases: & 3 & - & - & 3 & 9.000 & $0.011^{*}$ \\
\hline Right kidney and right lower ureteric stones & 1 & - & - & 1 & & \\
\hline Right kidney and right mid ureteric stones & 1 & - & - & 1 & & \\
\hline Right vesicouretric stone & 1 & - & - & 1 & & \\
\hline
\end{tabular}

Table (5): Shows the sensitivity, specificity, PPV, NPV, accuracy of MDCT in the current study.

\begin{tabular}{lcccc}
\hline & $\begin{array}{c}\text { Appendicular } \\
\text { diseases }\end{array}$ & $\begin{array}{c}\text { Other acute } \\
\text { GIT diseases }\end{array}$ & $\begin{array}{c}\text { Acute } \\
\text { gynecological diseases }\end{array}$ & $\begin{array}{c}\text { Acute urological } \\
\text { diseases }\end{array}$ \\
\hline Sensitivity (\%) & 88 & 100 & 83 & 100 \\
Specificity (\%) & 100 & 100 & 100 & 100 \\
PPV (\%) & 100 & 100 & 100 & 100 \\
NPV (\%) & 87 & 100 & 96 & 100 \\
Accuracy $(\%)$ & 93.33 & 100 & 96.67 & 100 \\
\hline
\end{tabular}

\section{Discussion}

Right lower quadrant abdominal pain is standout amongst the most difficult clinical presentations, including probably serious conditions which will necessitate emergency surgery. There are wide variants that simulate acute appendicitis when the patient is presented with right lower quadrant abdominal pain. These include other appendiceal diseases, other gastrointestinal conditions, urological diseases, and, in females, gynecologic diseases and conditions related to pregnancy [1].

Clinical examination stays an essential component of assessing a patient with supposed acute appendicitis. The diagnostic accuracy of clinical examination can reach $78 \%$ to $92 \%$ in male patients and $58 \%$ to $85 \%$ in female patients. The lesser diagnostic accuracy in women is most likely because gynecologic and obstetric diseases introduced with right lower quadrant abdominal pain [10]

Imaging is currently at the front in assessing and diagnosing patients with right lower quadrant pain, thus guiding appropriate clinical management. At the point when the ultrasound findings are vague, computed tomography can give a quick and conclusive diagnosis. As a result of its special accuracy, CT has elicited in several radiology divisions as the essential imaging technique with supposed acute appendicitis [11,12].

The improvement of MSCT and new progressions in the reconstruction software system had permitted fast, high-resolution imaging of the whole abdomen and pelvis leading to Multiplanar 
Reconstructions (MPRs) with a spatial resolution like that of the axial plane [13].

In our study, every patient examined by MSCT beginning from the dome of the diaphragm till the symphysis pubis on a single breath hold, this agrees with Purysko AS et al., [1], who said restricted CT data acquisitions over the lower abdomen and pelvis to assess the right lower quadrant pain can lead to partial or thoroughly missing of the appendix. Therefore, examining the total abdomen and pelvis start from the dome of the diaphragm until the pubic symphysis during one breath hold is suggested, as this can probably enhance recognition of different reasons of the pain.

Group A (acute appendicitis and appendiceal complications) had the largest number of patients included in the study representing $56.6 \%$, the second group in our study was Group C (acute gynecological diseases) representing $20 \%$, then Group B (other acute gastrointestinal diseases) representing $13.3 \%$, the least one was Group D (acute urological diseases) representing 10\% of the studied sample.

Acute appendicitis and appendiceal complications (Group A):

In the current study, appendicitis and appendiceal complications instituted the major portion of right lower quadrant diseases, constituting $56.6 \%$ (17 patients). This agrees with Kaddah RO et al., [14], who said in the research of 350 patients the most prevalent group was acute appendicitis and appendiceal complications involved 208 patients about $59.4 \%$ of a total number of cases. However conflict with Dustin et al., [15], who said in the research of 1571 patients the most common group involved non-appendiceal gastrointestinal diseases represented $46.0 \%$.

In our study, the perforated appendix was the most common complication of appendicitis. This agrees with Jordan JS et al., [16], who mentioned that the perforation of the appendix was the most common complication of acute appendicitis, it is depending on the body's response and the stage of evolution of the disease.

The most common MDCT finding in the patients with appendicular diseases was increased appendiceal diameter in 14 patients $(82.35 \%)$, the second common MDCT finding was stranding of fat planes in 10 patients (58.82\%). The least MSCT findings in the patients with appendicular complications were increased mural thickening of the cecum and terminal ileum, also the presence of loculated fluid collections with marginal enhancement \pm air foci which were presented in 2 patients $(11.76 \%)$. This agrees with Patel NB et al., [10], who said CT features of acute appendicitis usually reveal the intensity of inflammation as moderate cases have delicate imaging features which include a slightly enlarged, fluid-filled appendix estimating 5 to $6 \mathrm{~mm}$ in maximum diameter and without considerable surrounding appendiceal fat stranding. Classically, acute inflammation of the appendix presented with an increased appendiceal diameter of $\geq 7 \mathrm{~mm}$, enhancement of the appendiceal wall, and surrounding inflammatory change, infrequently with the presence of an appendicolith.

In our study, MSCT had a sensitivity of $88 \%$, specificity of $100 \%$ and an accuracy of $93.33 \%$ of diagnosing acute appendicitis. MSCT results correlated well with the surgical and histopathological findings which the final diagnosis was based on them. This agrees with Patel NB et al., [10], who said computed tomography imaging has established being a greatly valuable and precise technique for diagnosis of acute appendicitis, with sensitivities from $90 \%$ to $100 \%$, specificities from $91 \%$ to $99 \%$ and accuracies from $94 \%$ to $98 \%$.

In agreement with Naidoo $P$ et al., [11], CT diagnosis of appendicitis was challenging in the cases with lack of intra-abdominal fat (thin patients) or unusual location of the cecum or appendix.

\section{Other acute GIT conditions (Group B):}

In the present study, the $\mathrm{CT}$ findings of right colonic and cecal diverticulitis were multiple hyperdense outpouchings (diverticulae) noted arising from the cecal wall and ascending colon, with surrounding mild fat stranding and minimal fluid collection. In agreement with Naidoo $\mathrm{P}$ et al., [11], who said CT is an effective imaging modality that enables prompt diagnosis of diverticulitis and its complication. This disagrees with Purysko AS et al., [1], who said the differentiation of diverticulitis from malignant lesions including the cecum and right colon may be challenging or in particular patients are not possible based on computed tomography findings.

In the current study, the CT findings of ileocecal intussusception in the adult patient over intraluminal lipoma (intussusception is uncommon in an adult) were bowel-within-bowel configuration and the mesentery was seen forming a crescent of tissue around the compressed innermost lumen. The leading point was seen in the ileum, formed by fat density lesion (confirmed to be lipoma). These CT findings were diagnostic for ileocecal intussuscep- 
tion. This agrees with Purysko AS et al., [1], who said MDCT is the methodology of choice with the most diagnostic accuracy. Furthermore, intussusception is uncommon in adults representing fewer than 5\% of intussusception patients. In the majority of cases, there is a secondary pathology such as a benign or malignant neoplastic lesion which acts as a leading point.

In the present study, there were 2 patients with cecum cancer who presented by ARLQP, one of them complicated by perforation and abscess formation. The diagnosis confirmed by histopathology, both patients had adenocarcinoma. There were appear in contrast $\mathrm{CT}$ as focal enhancing soft tissue masses was seen involving the cecum, they were associated with multiple enlarged lymph nodes and in the complicated case, there was a loculated fluid collection at paracolic gutter with air foci and multiple hyperdense foci. This agrees with Purysko AS [1], who stated that acute right lower quadrant pain may be the first presentation of malignant lesions including the ileocecal area. Malignant lesions more frequently seem on CT as a focal mass with shouldering and is usually associated with enlargement of the adjacent lymph nodes. They additionally said separation between acute inflammatory disorders and malignancy at CT is not generally a simple work, as the CT findings can overlap.

In the current study, MSCT was diagnostic in 3 patients with other acute GIT diseases included 1 patient with right-sided diverticulitis, 1 patient with cecum cancer and 1 patient with ileocecal intussusception. MSCT was suggestive in 1 patient had cecum cancer with perforation and abscess formation. MSCT had a sensitivity of $100 \%$, specificity of $100 \%$, and an accuracy of $100 \%$ of diagnosing acute GIT diseases included in the current study. This agrees with Bassiouny $\mathrm{RH}$ et al., [17], who said CT over different modalities is precisely determined the bowel wall and also outlines the surrounding soft tissues and nearby structures. CT may not show delicate superficial mucosal alterations. However, it is an extremely sensitive technique for the recognition of intramural pathology and extraluminal expansion of colonic pathology.

\section{Acute gynecological diseases (Group C):}

In the present study, acute gynecological diseases group was the second most frequent group representing $20 \%$ of right lower quadrant diseases. This agrees with Hatipoglu S [18], who said gynecological diseases must be taken in thought while the women of reproductive age presented with acute right lower quadrant abdominal pain. In women of reproductive age, gynecological pathologies can mimic acute appendicitis in the physical findings.

In our study, MSCT in acute gynecological diseases was diagnostic in 2 patients of $6(33.3 \%)$, suggestive in 3 patients (50\%) and was false negative in 1 patient (16.7\%). In our study, MSCT had a sensitivity of $83 \%$ (the least sensitivity of CT compared to other groups), specificity of $100 \%$ and accuracy of $96.67 \%$ of diagnosing acute gynecological diseases included in the current study. This agrees with Iraha, Y et al., [19], who said CT findings of gynecologic emergencies are occasionally nonspecific and may lead to misinterpretation. But disagrees with Kaddah RO et al., [14], who said CT is often utilized as the primary imaging technique of acute gynecological diseases and identification of features of gynecological complications.

\section{Acute urological diseases (Group D):}

In our study, all patients with acute urinary tract obstruction were scanned without contrast. This agrees with Heller MT et al., [20], who said assessment for urolithiasis by MDCT is better made without contrast because of the extreme contrast differentiate between the radiopaque stone and the nearby soft tissues. But, not whole calculi are radiopaque.

In the present study, MSCT was demonstrated (diagnostic) for acute urological diseases in all patients included in this group. MSCT had a sensitivity of $100 \%$, specificity of $100 \%$, and an accuracy of $100 \%$ of diagnosing acute urological diseases included in the current study. This agrees with Urban BA [21], who said CT gives a fast and correct exam for the existence of urolithiasis and associated perinephric fat stranding and edema give evidence for the presence of an acute obstruction. Focal stranding around the ureter can even help restrict subtle calculi.

\section{Conclusion:}

MSCT has appeared as the technique of choice for assessment of patients with numerous conditions causing the right lower quadrant abdominal pain. MSCT is a particularly useful noninvasive method for diagnosing and managing not only the most known reasons such as appendicitis in addition to less familiar conditions. Multiplanar reformatting permits illustration of the structures located within the right iliac fossa and also their pathological conditions. Radiologists should be aware of all the conditions including the right iliac fossa to ensure 
accurate diagnosis and proper management for the patient.

\section{Competing interests:}

The authors pronounce that they have no competing interests.

\section{References}

1- PURYSKO A.S., REMER E.M., FILHO H.M. LEÃO, et al.: Beyond Appendicitis: Common and uncommon Gastrointestinal causes of Right Lower Quadrant Pain at multidetector CT. Radiographics, 31 (4): 927-47, 2011.

2- CHANG P.T., SCHOOLER G.R. and LEE E.Y.: Diagnostic errors of right lower quadrant pain in children: Beyond appendicitis. Abdominal imaging, 40 (7): 2071-90, 2015.

3- HATIPOGLU S., HATIPOGLU F. and ABDULLAYEV R.: Acute right lower abdominal pain in women of reproductive age: Clinical clues. World Journal of Gastroenterology, 20 (14): 4043-9, 2014.

4- GANS S.L., POLS M.A., STOKER J., et al.: Guideline for the diagnostic pathway in patients with acute abdominal pain. Digestive surgery, 32 (1): 23-31, 2015.

5- BARGER R.L. and NANDALUR K.R.: Diagnostic performance of magnetic resonance imaging in the detection of appendicitis in adults: A meta-analysis. Academic Radiology, 17 (10): 1211-6, 2010.

6- ROSEN M.P., SANDS D.Z., LONGMAID H.E., et al.: Impact of abdominal CT on the management of patients presenting to the emergency department with acute abdominal pain. American Journal of Roentgenology, 174 (5): 1391-6, 2000.

7- PURYSKO A.S., REMER E.M., FILHO H.M. LEÃO, et al.: Beyond Appendicitis: Common and uncommon Gastrointestinal causes of Right Lower Quadrant Pain at multidetector CT. Radiographics, 31 (4): 927-47, 2011.

8- GANGULI S., RAPTOPOULOS V., KOMLOS F., et al.: Right Lower Quadrant Pain: Value of the non-visualized Appendix in Patients at Multidetector CT. Radiology, 241 (1): 175-80, 2006.

9- HOWELL J.M., EDDY O.L., LUKENS T.W., et al.: Clinical policy: Critical issues in the evaluation and management of emergency department patients with suspected appendicitis. Annals of Emergency Medicine, 55 (1): 71-116, 2010.
10- PATEL N.B. and WENZKE D.R.: Evaluating the Patient with Right Lower Quadrant Pain. Radiologic Clinics of North America, 53 (6): 1159-70, 2015.

11-NAIDOO P. and SINGH B.: Current Radiological Strategies for the Assessment of Right Lower Quadrant Abdominal Pain. South African Journal of Radiology, 18 (1): 115, 2014.

12- MARINCEK B.: Non-traumatic abdominal emergencies: Acute abdominal pain: Diagnostic strategies. European Radiology, 12 (9): 2136-50, 2002.

13- NEVILLE A.M. and PAULSON E.K.: MDCT of acute appendicitis: Value of coronal reformations. Radiology, 34 (1): 42-8, 2008.

14- KADDAH R.O. and AYAD A.M.: Multidetector CT evaluation of alternative diagnosis of clinically suspected acute appendicitis, appendicular and nonappendicular lesions. Egyptian Journal of Radiology and Nuclear Medicine, 47 (3): 669-77, 2016

15- POOLER B.D., LAWRENCE E.M. and PICKHARDT P.J.: Alternative diagnoses to suspected appendicitis at CT. Radiology, 265 (3): 733-42, 2012.

16- JORDAN J.S., KOVALCIK P.J. and SCHWAB C.W.: Appendicitis with a palpable mass. Ann. Surg., 193: 2279, 2002.

17- BASSIOUNY R.H. and ABU EL-MAATI A.A.: Acute right lower quadrant pain beyond acute appendicitis: MDCT in evaluation of benign and malignant gastrointestinal causes. The Egyptian Journal of Radiology and Nuclear Medicine, 45 (3): 627-40, 2014.

18- HATIPOGLU S., HATIPOGLU F. and ABDULLAYEV R.: Acute right lower abdominal pain in women of reproductive age: Clinical clues. World Journal of Gastroenterology, 20 (14): 4043-9, 2014.

19- IRAHA Y., OKADA M., IRAHA R., et al.: CT and MR Imaging of Gynecologic Emergencies. RadioGraphics, 37 (5): 1569-86, 2017.

20- HELLER M.T. and HATTOUM A.: Imaging of Acute Right Lower Quadrant Abdominal Pain: Differential Diagnoses beyond Appendicitis. Emergency Radiology, 19 (1): 61-73, 2012.

21- URBAN B.A. and FISHMAN E.K.: Tailored Helical CT Evaluation of Acute Abdomen. RadioGraphics, 20 (3): 725-49, 2000 


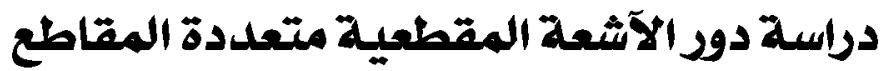

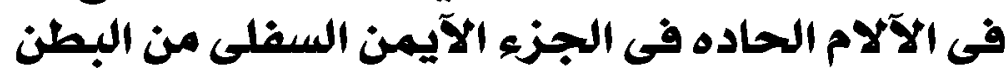

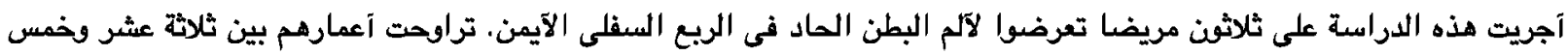

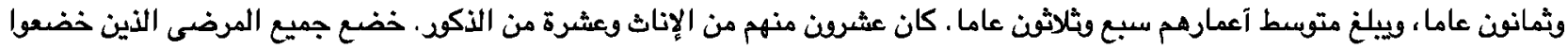

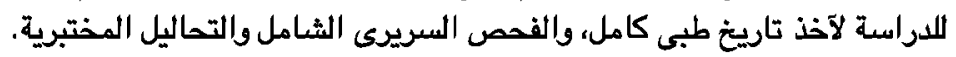

شئل التشخيص النهائى للمرضى على آساس الآشعُة المقطعية متعددة الحزم، النتائج السريرية، نتائج العمليات الجراحية ونتائج العينة النسيجية:

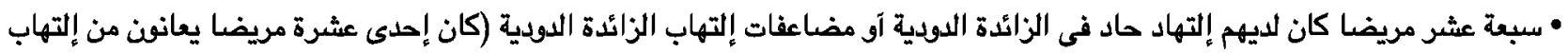

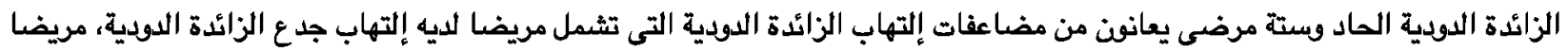

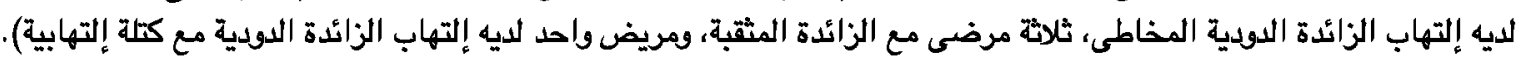

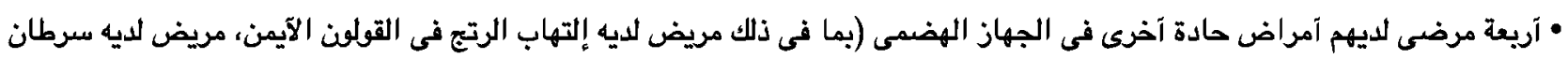

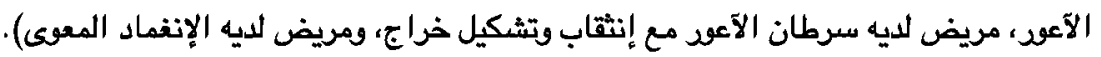

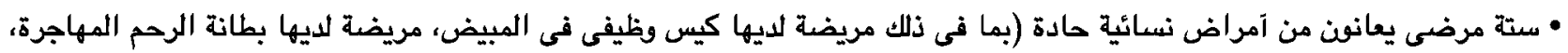

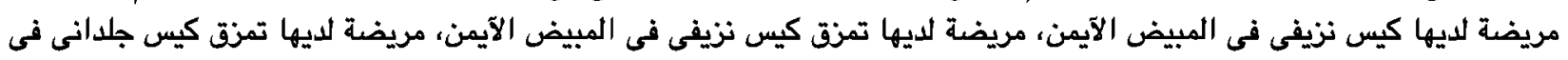

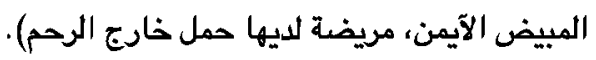

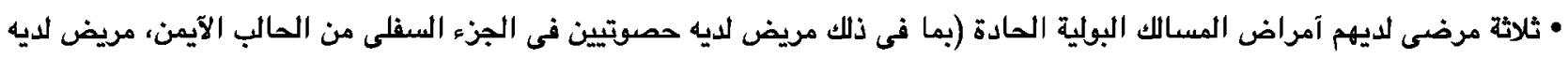
حصوة فى الجزء المثانى الحالبى، مريض لائ حصوات في الكلية اليمنى والحالب الآيمن).

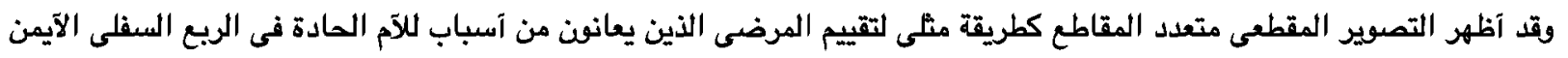

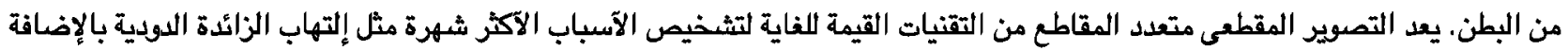

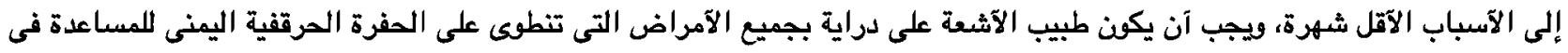

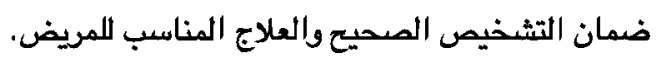

